\title{
Hepatic arterial infusion but not systemic application of cetuximab in combination with oxaliplatin significantly reduces growth of CC531 colorectal rat liver metastases
}

\author{
Jens Sperling • Thilo Schäfer • Anna Benz-Weißer • \\ Christian Ziemann • Claudia Scheuer • Otto Kollmar • \\ Martin K. Schilling • Michael D. Menger
}

Accepted: 21 November 2012 / Published online: 15 December 2012

(C) The Author(s) 2012. This article is published with open access at Springerlink.com

\begin{abstract}
Purpose Systemic chemotherapy still represents the gold standard in the treatment of irresectable colorectal liver metastases. Modern anticancer agents like the monoclonal antibody cetuximab have improved the outcome of patients in clinical studies. As hepatic arterial infusion (HAI) is capable to potentially increase the anticancer effect of cytostatics, we herein studied whether HAI of cetuximab (CE) as a single agent or in combination with oxaliplatin (OX) exerts increased anticancer effects compared to the systemic application (SYS) of the drugs. Methods WAG/Rij rats were randomized to eight groups and underwent 10 days after subcapsular hepatic tumor implantation either HAI or SYS of CE, OX, or the combination of both agents $(\mathrm{CE}+\mathrm{OX})$. Saline-treated animals served as controls. Tumor volume was measured at days 10 and 13 using threedimensional ultrasound. On day 13, liver and tumor tissue was sampled for histological and immunohistochemical analysis. Results In controls, the tumor volume significantly increased from day 10 to 13. Application of OX alone via HAI or SYS did not inhibit tumor growth compared to controls. SYS of CE or
\end{abstract}

J. Sperling $(\bowtie) \cdot$ T. Schäfer $\cdot$ C. Ziemann $\cdot$ O. Kollmar •

M. K. Schilling

Department of General, Visceral, Vascular and Pediatric Surgery,

University of Saarland,

66421 Homburg/Saar, Germany

e-mail: jens.sperling@med.uni-goettingen.de

\section{A. Benz-Weißer · C. Scheuer • M. D. Menger}

Institute for Clinical \& Experimental Surgery, University of Saarland,

Homburg/Saar, Germany

Present Address:

J. Sperling $\cdot$ O. Kollmar

Department of General and Visceral Surgery,

University Medical Center, Georg August University Göttingen,

Robert-Koch-Strasse 40,

37075 Göttingen, Germany
$\mathrm{CE}+\mathrm{OX}$ did also not reduce tumor growth. In contrast, HAI of $\mathrm{CE}$ and $\mathrm{CE}+\mathrm{OX}$ significantly inhibited tumor growth. HAI of CE significantly reduced tumor vascularization as measured by the number of platelet endothelial cell adhesion molecule-1positive cells and significantly increased the number of apoptotic tumor cells as measured by the cellular caspase-3 expression. Conclusion HAI of CE and CE + OX reduces tumor growth of colorectal rat liver metastases involving the inhibition of angiogenesis and induction of tumor cell apoptosis.

Keywords Colorectal liver metastases $\cdot$ Locoregional chemotherapy $\cdot$ Hepatic arterial infusion $\cdot$ Systemic chemotherapy $\cdot$ Monoclonal antibody

\section{Introduction}

Colorectal cancer is one of the most common malignancies in the western world and has rising incidence in Asia either [1]. About $50 \%$ of colorectal cancer patients develop liver metastases with a statistical 5-year survival of 10-20\% [2]. Today, due to novel and multimodal therapies, treatment options for hepatic colorectal metastases are manifold. However, the patient population is very inhomogeneous. In patients with irresectable liver metastases, the 5-year survival rate is almost zero. In contrast, patients with resectable metastases can even be healed by surgical treatment.

Systemic chemotherapy plays a key role in colorectal cancer patients, regardless of whether the therapeutic intention is curative or palliative. The response rate of the classic intravenous 5-fluorouracil/folinic acid chemotherapy regime is about $20 \%$. In the past years, it has been shown that by adding oxaliplatin or irinotecan (FOLFOX and FOLFIRI regimens) the response rate is doubled [3]. Cetuximab, a chimeric monoclonal IgG1 antibody directed against the 
ligand-binding domain of the epidermal growth factor receptor (EGF-R), belongs to a group of novel anti-cancer agents. Its additional application has led to a further improvement of the outcome of metastatic colorectal cancer treatment, albeit restricted to patients with wild-type K-ras status [4-6]. However, even with modern systemic chemotherapy regimens, the 2-year survival rate still does not exceed $40 \%$ [7].

Despite an ongoing discussion about the oncological benefit of hepatic arterial infusion (HAI), it is known that HAI is capable of augmenting the antineoplastic effects of anticancer agents, and therefore, it is recommended from some centers [8-11]. A recent Cochrane review of Mocellin et al. concluded that the future of HAI seems to be linked to the delivery of novel cancer agents or drug combinations [12]. Accordingly, we herein studied in a rat liver metastasis model, whether HAI compared to SYS of cetuximab with or without the combination of oxaliplatin is capable of increasing the antitumor effect of these agents.

\section{Materials and methods}

\section{Binding of cetuximab}

To analyze the specific binding of cetuximab to the surface of the cells of the rat colon carcinoma cell line CC531, in vitro immunocytochemical fluorescence staining was performed. After fixing with $4 \%$ phosphate-buffered formalin and blocking of unspecific binding sites with $1 \%$ donkey serum, CC531 cells were incubated with the primary antibody concentrate cetuximab for $2 \mathrm{~h}$ at $37^{\circ} \mathrm{C}$. A Cy-3-labeled donkey antihuman $\mathrm{IgG}$ antibody was incubated for $30 \mathrm{~min}$ at the concentration of 1:50 (Jackson by Dianova GmbH, Hamburg, Germany) and was used as secondary antibody. Cell nuclei were stained with $2 \mu \mathrm{g} / \mathrm{mL}$ bisbenzimide (Sigma, Taufkirchen, Germany). The cells were visualized by fluorescence microscopy (Fig. 1). In four separate experiments, the number of positively stained cells was counted in 20 high-power fields (each experiment) and is given in percent of all cells analyzed.

In vitro cell viability analysis

To assess the effect of cetuximab on the viability of cultured CC531 cells, a water-soluble tetrazolium (WST)-1 assay was performed according to the manufacturer's instructions (Roche, Mannheim, Germany). For this purpose, $1 \times 10^{4}$ cells per well were seeded in $100 \mu \mathrm{L}$ RPMI medium with $20 \%$ fetal calf serum, $100 \mathrm{U} / \mathrm{mL}$ penicillin, and $0.1 \mathrm{mg} / \mathrm{mL}$ streptomycin (PAA, Cölbe, Germany) on a 9-well plate. After overnight culturing at $37{ }^{\circ} \mathrm{C}$ in a humidified atmosphere containing $5 \%$ $\mathrm{CO}_{2}$, cells were treated with cetuximab in concentrations of 1 , $10,100,1,000,2,500$, or $5,000 \mu \mathrm{g} / \mathrm{mL}$ for $24 \mathrm{~h}$. WST-1 reagent $(10 \mu \mathrm{L})$ was added, and the absorption was measured after
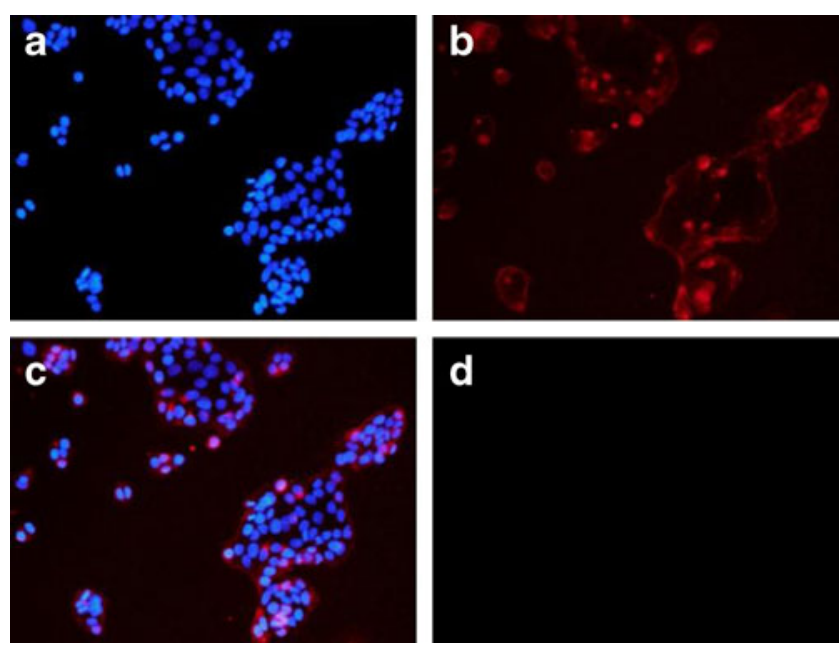

Fig. 1 Immunocytochemical fluorescence microscopy of CC531 cells in vitro. a The staining of the nuclei of the cells (cells are stained blue). b The binding of cetuximab (stained red) on the CC531 cells; c the merge of $\mathbf{a}$ and $\mathbf{b}$. d The negative control

$30 \mathrm{~min}$ at $450 \mathrm{~nm}$ and at $620 \mathrm{~nm}$ as reference, using a microplate reader. The measured data were corrected to the blank values without cells.

Drugs

Cetuximab was given in a dose of $125 \mathrm{mg} / \mathrm{m}^{2}$, and oxaliplatin, in a dose of $85 \mathrm{mg} / \mathrm{m}^{2}$. To calculate the body surface area, we used "Meeh's formula," assuming that it is proportional to the two-thirds power of the body weight. The formula reads as follows: $A=K \times W^{2 / 3}$, where $A$ represents the body surface area; $K$, an animal specific constant; and $W$, the body weight. In the present study, a $K$ value of 9.1 was used [13].

Rat liver metastasis model

All experiments were approved by the local governmental ethic committee. Forty-eight male WAG/Rij rats with a mean body weight of $267.5 \pm 5.9 \mathrm{~g}$ were used to perform the experiments. Animals were randomized in eight groups ( $n=6$ each) and kept in a temperature- and humidity-controlled 12-h light/dark cycle environment with free access to water and standard laboratory chow (Altromin, Lage, Germany). For the induction of colorectal liver metastases, a median laparotomy was performed under ether anesthesia. Using a $27 \mathrm{G}$ needle (Omnicon F, Braun, Melsungen, Germany) $5 \times 10^{5}$ cells of the syngeneic CC531 colon carcinoma cell line were injected under the capsule of the lower surface of the left liver lobe. Laparotomy was closed by a one-layer running PDS 4-0 suture (Ethicon/Johnson \& Johnson MEDICAL GmbH, Norderstedt, Germany).

Surgical procedure

Ten days after tumor cell implantation, animals were relaparotomized under ether anesthesia. For the HAI 
procedure, the gastroduodenal artery was cannulated (ID $0.28 \mathrm{~mm}$, Portex, Hythe, UK). The tip of the catheter was positioned at the common hepatic artery. During the HAI procedure, the hepatic artery was not occluded and showed orthograde blood flow. After the HAI procedure, the catheter was removed, and the gastroduodenal artery was ligated. For the SYS procedure, the subhepatic vena cava was punctured with a 23-G needle (Troge Medical GmbH, Hamburg, Germany) according to previously published standards [14].

\section{Experimental protocol}

Animals were randomized to eight groups ( $n=6$ each) including four subgroups of animals undergoing HAI and four subgroups undergoing SYS. After tumor cell implantation (day 0 ), relaparotomy was performed on day 10 , and animals received either cetuximab (CE), oxaliplatin (OX), or the combination of both (CE + OX) via HAI or SYS. Sham controls received an equivalent amount of $0.9 \%$ saline solution (Braun, Melsungen, Germany). HAI or SYS procedure was performed for a time period of 1 min followed by ultrasound imaging. Three days later (day 13), animals underwent relaparotomy for final ultrasound imaging. Animals were sacrificed, and tissue samples were asserved for histological and immunohistochemical analysis. The body weight of the animals was measured on days 0,10 , and 13 to determine weight reduction due to the treatment.

\section{Three-dimensional ultrasound imaging}

For evaluation of the tumor volume, the 40-MHz ultrasound probe of the Vevo 770 high-resolution imaging system (VisualSonics, Inc., Toronto, Ontario, Canada) was used. Ultrasound imaging was performed on the liver surface on days 10 and 13. For three-dimensional imaging, parallel two-dimensional images were acquired in $50-\mu \mathrm{m}$ intervals controlled by a stepping motor. The three-dimensional reconstruction was achieved by off-line outlining the tumor dimension every $200 \mu \mathrm{m}$ on the two-dimensional images. Using these data, the integrated software of the ultrasound device produced a polygonal three-dimensional image and calculated the tumor volume.

\section{Sampling and assays}

Via puncture of the subhepatic vena cava, venous blood samples were taken at day 10 before drug administration and at day 13 before ultrasound imaging. As indicators of hepatocellular injury, aspartate aminotransferase (ASAT), alanine aminotransferase (ALAT) and glutamate dehydrogenase (GLDH) serum activities were determined using routine spectrophotometry.
Histology

Tissue specimens of the tumor and the surrounding liver parenchyma were fixed in $4 \%$ phosphate-buffered formalin and embedded in paraffin. Histological analysis of hepatocellular injury, venular endothelial detachment and venular fibrin clotting, was performed using sections of $5 \mu \mathrm{m}$ stained with hematoxylin-eosin. Hepatocellular injury was determined by analysis of hepatocellular vacuolization with a semiquantitative score: $0=$ none; $1=$ mild; $2=$ moderate; and $3=$ severe. Venular endothelial detachment was assessed by counting the number of venules with detachment of endothelial lining cells and is given in percent of all venules analyzed. Accordingly, the number of venules with fibrin clots was counted, and fibrin clotting is given in percent of all venules analyzed.

\section{Immunohistochemistry}

For immunohistochemistry tissue slides were deparaffinized, and proteins were unmasked with citrate buffer at a $\mathrm{pH}$ of 6 . The endogenous peroxidases were blocked with $3 \% \mathrm{H}_{2} \mathrm{O}_{2}$ in methanol, and unspecific proteins were blocked with $3 \%$ goat serum.

Cleaved caspase-3 (cysteine-aspartic proteases) as an indicator of apoptotic cell death was used. Fivemicrometer sections of paraffin-embedded tumorbearing liver specimens were incubated overnight at room temperature with a rabbit polyclonal anti-cleaved caspase-3 antibody (1:50, Cell Signaling Technology, Frankfurt, Germany). As secondary antibody, a peroxidaseconjugated goat anti-rabbit IgG antibody (1:100, Dianova, Hamburg, Germany) was used. 3.3'-Diaminobenzidine was used as chromogen. The sections were counterstained with hemalaun. Positively stained cells were counted in 25 highpower fields (HPF) per specimen and are given as number per HPF.

Proliferating cell nuclear antigen (PCNA) served as an indicator of cell proliferation. Five-micrometer sections of paraffin-embedded specimens were incubated for $18 \mathrm{~h}$ at $4{ }^{\circ} \mathrm{C}$ with a mouse monoclonal anti-PCNA antibody (1:50; Dako, Hamburg, Germany). For development of PCNA, a peroxidase-conjugated goat anti-mouse IgG antibody (1:100; Dianova) was incubated for $30 \mathrm{~min}$. 3.3'-Diaminobenzidine was used as chromogen, and hemalaun was used for counterstaining. Sections were analyzed using a score ranging from 0 to 4 of PCNA-positive cells $(0 \leq 1 \%, 1=1-$ $10 \%, 2=10-30 \%, 3=30-50 \%, 4 \geq 50 \%$ of PCNA-positive cells).

Platelet endothelial cell adhesion molecule-1 (PECAM-1; CD31) served as an indicator for vascularization. For immunohistochemical detection of PECAM-1 expression, a primary mouse anti-rat antibody (1:500; clone 
TLD-3 A12, Serotec) was used, and a peroxidaseconjugated goat anti-mouse antibody (Dianova) was used as secondary antibody. PECAM-1-positive blood vessels were given as number per HPF (counted in 25 HPF per section).

\section{Statistical analysis}

All values are expressed as mean \pm SEM. After analysis of the normal distribution of data and homogeneity of variance, differences between the groups were calculated by one-way analysis of variance followed by the Student-NewmanKeuls test. The pairwise comparison was performed by Student's $t$ test. Overall statistical significance was set at $p<0.05$. Statistical analysis was performed with the use of SigmaStat (SPSS, Inc., Chicago, USA).

\section{Results}

\section{Binding of cetuximab}

Specific in vitro binding experiments using immunocytochemical fluorescence staining showed that cetuximab binds to the surface of CC531 cells (Fig. 1). Quantitative analysis revealed $92.5 \pm 0.4 \%$ positively stained cells, indicating a high affinity of cetuximab to the CC531 cells.

In vitro cell viability after cetuximab exposure

After 30-min exposure of CC531 cells to 2,500 and $5,000 \mu \mathrm{g} / \mathrm{ml}$ cetuximab, the WST assay showed a significant reduction of cell viability to $\sim 12$ and $\sim 3 \%$ [optical density (OD) $0.034 \pm 0.003$ and $0.009 \pm 0.002$ ] compared to controls (OD $0.283 \pm 0.011$ ). Similar results were observed after 1-h exposure (OD $0.086 \pm 0.001$ and $0.012 \pm 0.001$ vs $0.446 \pm$ 0.002 ). Cetuximab concentrations of $<1,000 \mu \mathrm{g} / \mathrm{ml}$ did not significantly affect CC531 cell viability.

Metastatic tumor growth and general health conditions

After 10 days of tumor growth, all animals established a solitary tumor in the left liver lobe with a diameter of about 5 to $10 \mathrm{~mm}$. Signs of extrahepatic disease were not observed. Animals were not affected systemically by the malignant process. Analysis of the body weight could not detect a significant difference of weight change from days 0 to 13 between HAI- and SYS-treated animals (Table 1). Of interest, SYS of CE, CE + OX, and OX showed significantly less weight gain compared to SYS Sham. In contrast, after HAI only, OX alone showed a reduced weight gain compared to sham (Table 1).
Table 1 Body weight change (in percent) from days 0 to 13

\begin{tabular}{lll}
\hline Group & HAI & SYS \\
\hline Sham & $-2.1 \pm 0.4$ & $+7.3 \pm 2.2$ \\
CE & $+1.2 \pm 1.3$ & $-0.4 \pm 1.0^{*}$ \\
CE + OX & $-2.0 \pm 1.3$ & $-4.5 \pm 1.2^{*}$ \\
OX & $-6.9 \pm 1.9^{*}$ & $-4.3 \pm 1.6^{*}$
\end{tabular}

Weight change from days 0 to 13 in percent of the body weight at day 0 . Animals were treated either with hepatic arterial infusion or systemic application of saline (Sham), cetuximab, the combination of cetuximab and oxaliplatin, or oxaliplatin alone. There were no statistically significant differences comparing HAI to SYS. Mean \pm SEM

$H A I$ hepatic arterial infusion, $S Y S$ systemic application, $C E$ cetuximab, $C E+O X$ combination of cetuximab and oxaliplatin, $O X$ oxaliplatin

$* p<0.05$ vs Sham of the corresponding group

Metastatic tumor growth

From days 10 to 13 , tumor size increased by more than $50 \%$ in HAI controls (HAI Sham) and more than $40 \%$ in SYS controls (SYS Sham) without significant difference when comparing the two groups (Fig. 2). Oxaliplatin given as monotherapy via HAI (HAI OX) showed a slight but not significant inhibition of tumor growth compared to HAI
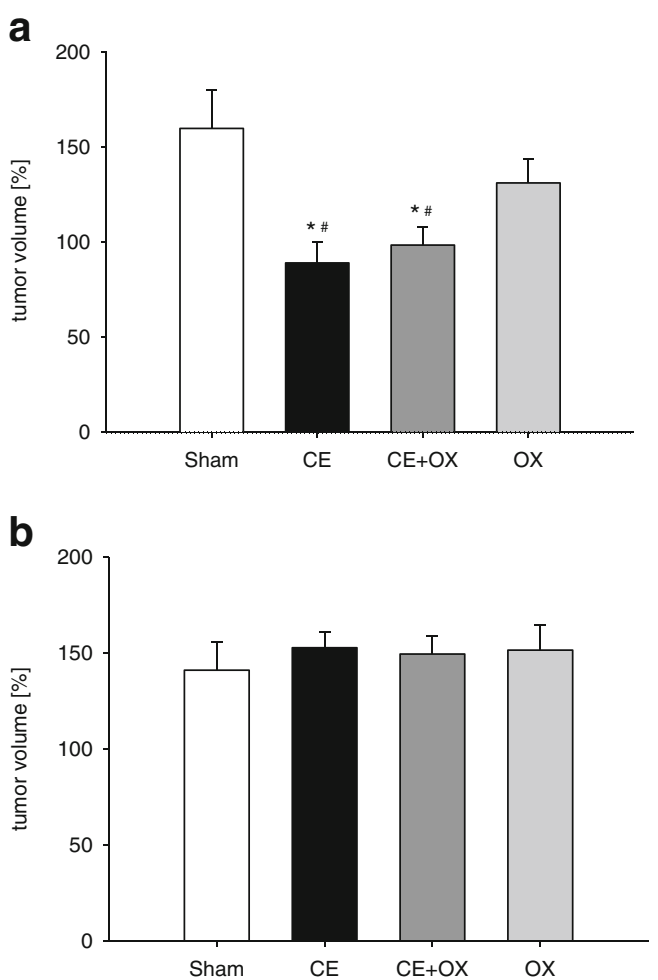

Fig. 2 a, b The tumor volume at day 13 in percent of the volume measured at day 10 after HAI (a) and SYS (b) of cetuximab $(C E)$, oxaliplatin $(O X)$, or the combination of both $(C E+O X)$. Animals undergoing HAI or SYS with saline served as controls (Sham). Data are given as mean \pm SEM; $* p<0.05$ vs Sham; ${ }^{\#} p<0.05$ vs corresponding SYS 
sham (Fig. 2), whereas SYS OX did not show any effect (Fig. 2). Of interest, HAI of cetuximab alone (HAI CE) or in combination with oxaliplatin (HAI CE + OX) significantly inhibited tumor growth compared to HAI sham and the corresponding SYS groups (Fig. 2).

Tumor cell proliferation

In all groups, tumors showed a high proliferation rate as measured by PCNA-positive immunohistochemistry. There was no substantial difference in tumor cell proliferation between HAI- and SYS-treated animals (Fig. 3). The proliferation rate within the surrounding liver tissue was significantly lower compared to the tumor tissue. However, there were also no differences between the groups (Fig. 3).

Apoptotic tumor cell death

Apoptotic cell death in the unaffected liver tissue was overall neglectable. Analysis of the number of apoptotic cells in the tumors revealed that sham controls and monotherapy with oxaliplatin did not show any relevant differences
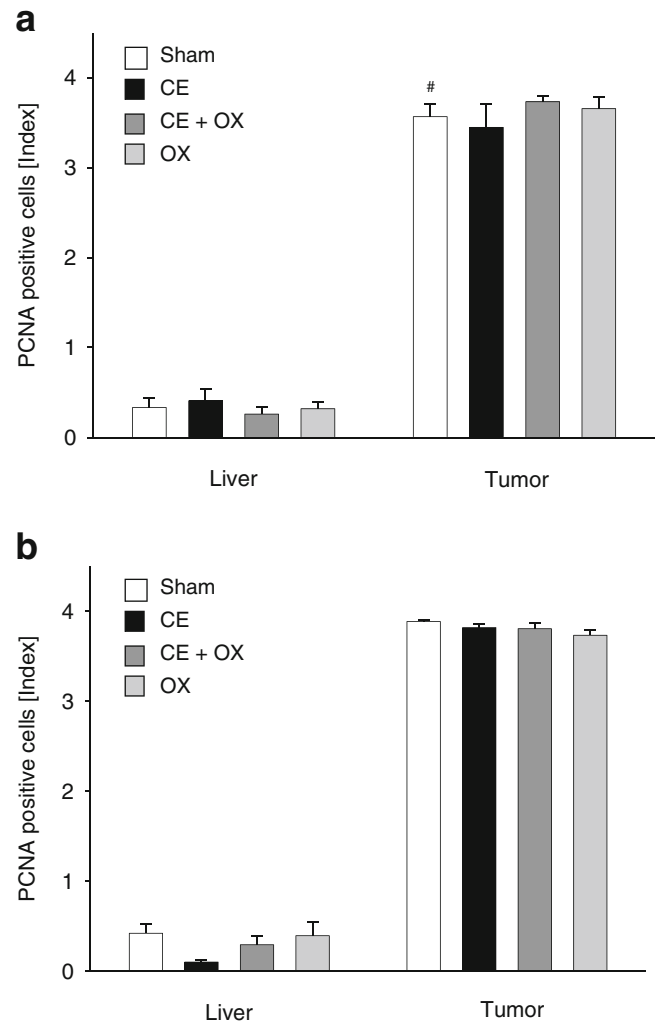

Fig. 3 a, b The data of the immunohistochemical analysis of proliferating nuclear cell antigen (score $0=<1 \%, 1=1-10 \%, 2=10-30 \%, 3=30-50 \%$, and $4 \geq 50 \%$ of PCNA-positive cells) of liver and tumor tissue of animals undergoing HAI (a) or SYS (b) with cetuximab $(C E)$, oxaliplatin $(O X)$, or the combination of both $(C E+O X)$. Animals undergoing HAI or SYS with saline served as controls (Sham). Data are given as mean $\pm \mathrm{SEM}$; ${ }^{\#} p<0.05$ vs corresponding SYS between HAI and SYS. Of interest, systemic application of the drugs did not show significant differences compared to SYS Sham (Fig. 4). In contrast, $\mathrm{CE}$ and $\mathrm{CE}+\mathrm{OX}$ via HAI induced a significant three- to fourfold increase of apoptotic cell death compared to both HAI Sham as well as SYS CE and SYS CE + OX (Fig. 4).

Tumor vascularization

In sham controls, the number of tumor vessels, indicated by PECAM-1-positive cells, was $11.9 \pm 0.9$ in HAI-treated tumors and $10.5 \pm 1.7$ per HPF in SYS-treated tumors. SYS OX reduced the number of blood vessels per HPF by about $40 \%$. HAI OX was even more effective and reduced the number of blood vessels by about $70 \%$ compared to sham control. SYS or HAI of CE and, in particular, HAI CE + OX were also highly effective in reducing the number of tumor blood vessels (Fig. 5).

Hepatocellular injury

Analysis of the liver enzymes ASAT and ALAT as indicators of hepatocellular injury at days 10 and 13 did not reveal
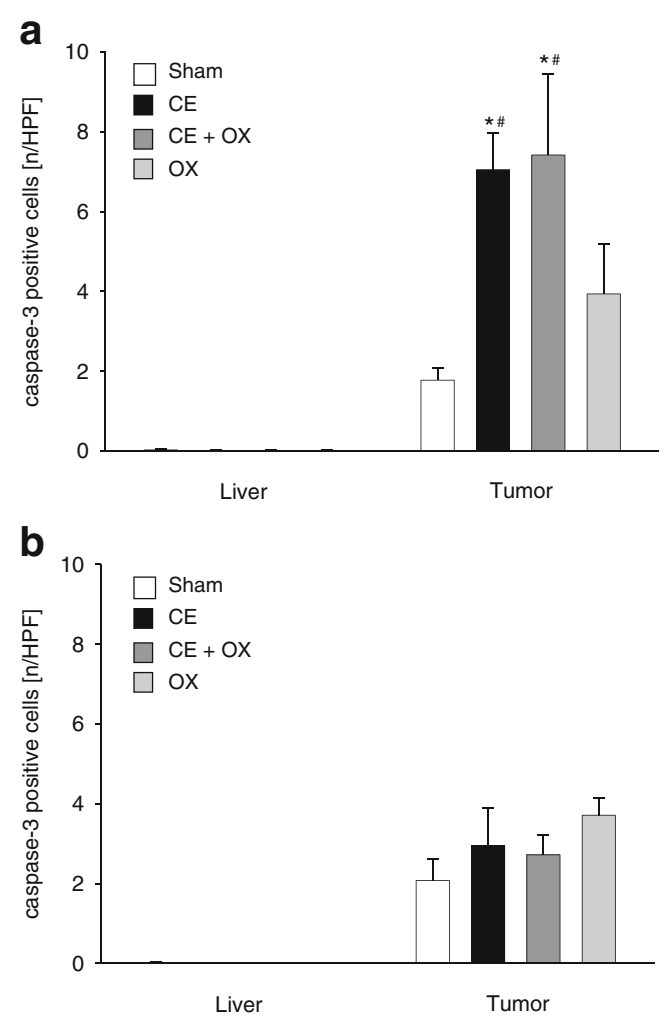

Fig. 4 a, b The quantitative analysis of cleaved caspase-3-positive cells of liver and tumor tissue (given as number per HPF) of animals undergoing HAI (a) or SYS (b) with cetuximab $(C E)$, oxaliplatin $(O X)$, or the combination of both (CE + OX). Animals undergoing HAI or SYS with saline served as controls (Sham). Data are given as mean \pm SEM; ${ }^{*} p<0.05$ vs Sham; ${ }^{*} p<0.05$ vs corresponding SYS 
a

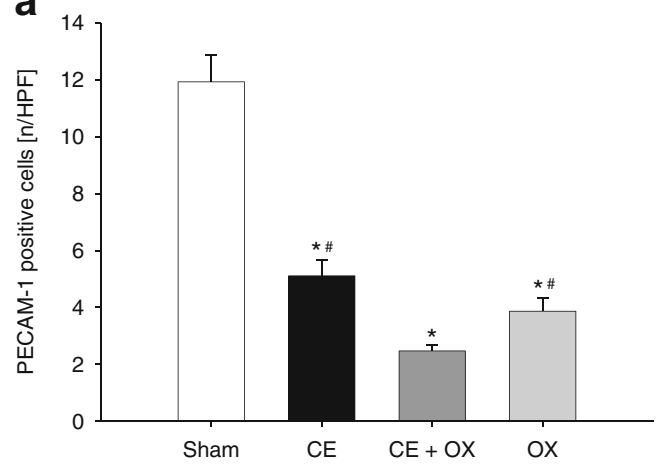

b

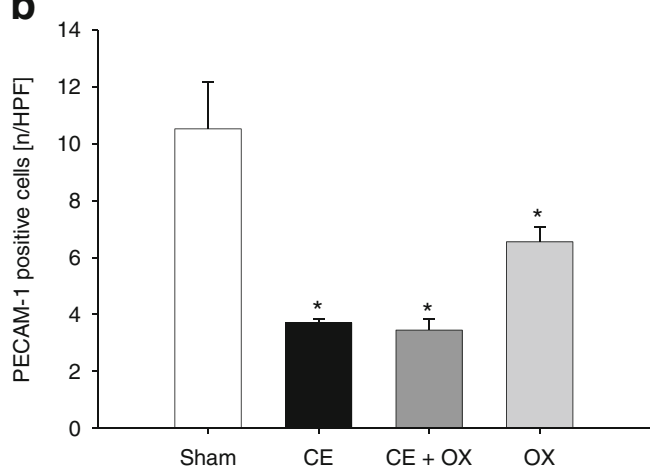

Fig. 5 a, b The number of PECAM-1-positive blood vessels per HPF in tumors of animals undergoing HAI (a) or SYS (b) with cetuximab $(C E)$, oxaliplatin $(O X)$, or the combination of both $(C E+O X)$. Animals undergoing HAI or SYS with saline served as controls (Sham). Data are given as mean $\pm \mathrm{SEM} ;{ }^{*} p<0.05$ vs Sham; ${ }^{*} p<0.05$ vs corresponding SYS

significant differences between the HAI and SYS groups (data not shown). Analysis of the GLDH activity from days 10 and 13 showed a slight increase after HAI CE + OX and HAI OX (Table 2).

Table 2 Liver enzyme GLDH (in units per liter) at days 10 and 13

\begin{tabular}{llllll}
\hline \multirow{2}{*}{ Group } & Day 10 & & & Day 13 & \\
\cline { 2 - 3 } \cline { 5 - 6 } & HAI & SYS & & HAI & SYS \\
\hline Sham & $22.3 \pm 7.1$ & $34.3 \pm 10.3$ & & $35.0 \pm 5.8$ & $22.3 \pm 6.5$ \\
CE & $49.9 \pm 9.7$ & $23.2 \pm 6.6$ & & $44.6 \pm 8.4$ & $22.9 \pm 9.8$ \\
CE + OX & $24.7 \pm 6.4$ & $38.6 \pm 14.2$ & & $72.2 \pm 5.1$ & $20.8 \pm 6.9 *$ \\
OX & $30.5 \pm 6.2$ & $35.2 \pm 5.9$ & & $59.8 \pm 34.8$ & $15.1 \pm 2.9$ \\
\hline
\end{tabular}

Animals were treated either with hepatic arterial infusion or systemic application of saline (Sham), cetuximab, or oxaliplatin alone or the combination of cetuximab and oxaliplatin. HAI of cetuximab and oxaliplatin led to a significant increase of GLDH from days 10 to 13 compared to the systemic administration form (SYS CE $+\mathrm{OX}$ ). Mean $\pm \mathrm{SEM}$

$H A I$ hepatic arterial infusion, $S Y S$ systemic application, $C E$ cetuximab, $O X$ oxaliplatin, $C E+O X$ combination of cetuximab and oxaliplatin, $H A I C E+O X$ HAI of cetuximab and oxaliplatin

${ }^{*} p<0.05$ vs HAI
Histomorphological analysis of hepatocellular vacuolization, endothelial detachment, or vascular fibrin clotting did not reveal relevant differences between HAI and SYS after Sham, OX, CE, and CE + OX treatment (data not shown).

\section{Discussion}

The major finding of the present study is that cetuximab via HAI but not via SYS as monotherapy or in combination with oxaliplatin is effective to inhibit tumor growth of colorectal liver metastases in the rat. Colorectal cancer is the second leading cause of cancer death worldwide. About $20 \%$ of the patients show synchronous hepatic metastases, and up to $30 \%$ develop metachronous disease [15]. Therefore, the control of this hepatic disease remains a challenging issue. Systemic chemotherapy is a substantial part of the treatment of colorectal liver metastases. Moreover, hepatic arterial infusion is used in some centers with different results [8-11]. In a recent Cochrane review, Mocellin et al. concluded that the future of HAI seems to be linked to the use of novel anticancer agents or drug combinations [12]. Bouchahda et al. also claimed that the role of HAI should be revisited using modern therapeutic approaches [16]. Thus, HAI is moving again in the focus of scientific interest in clinical and experimental studies and plays an increasing role in the treatment of liver-limited metastatic colorectal cancer [7, 14, 17-19]. HAI, as locoregional chemotherapy, bears the advantage to increase the local concentration of tumoricidal agents within liver metastases. The rationale for HAI is that hepatic metastases receive their nutritive blood supply mostly from the hepatic arterial system, while the hepatic tissue is fed predominantly by the portal venous blood flow [20]. Moreover, whereas the portal vein via the Glisson Trias directly drains into the liver sinusoids, part of the arterial blood at first drains into the peribiliary plexus before entering the sinusoidal system [21]. Tumor vessels of hepatic metastases are supplied by this arterial blood flow [22], which leads to a prolonged exposure time of drugs applied via the arterial system. This probably caused the increased antitumor effect seen after HAI compared to SYS in the present study [23]. Moreover, hepatic arterial drug application can lead to high extraction rates of drugs via the first-pass effect and consecutively less side effects [7]. Therefore, agents with high extraction rates are particularly attractive for HAI. While in former clinical trials, HAI was predominantly performed with floxuridine or 5-FU, newer trials included oxaliplatin with encouraging results $[8,9,14$, 24, 25].

Oxaliplatin, plays a key role in chemotherapy of colorectal cancer because of a large spectrum of anticancer activity together with mild toxicity [26-28]. However, in the present study, a measureable reduction of tumor growth was only 
seen in animals treated by HAI of cetuximab alone or in combination with oxaliplatin. HAI or SYS of oxaliplatin alone did not inhibit tumor growth in the present liver metastasis model. This is not surprising because, from clinical findings, it is known that oxaliplatin monotherapy exerts only minimal antineoplastic effects [29]. Accordingly, in clinical studies, oxaliplatin is not given as a single drug, but only in combination with other antineoplastic agents [29]. The present study was conducted as a "proof of principle" study, where a single application of the drugs in a short time period was chosen to evaluate whether HAI of the drug in the fast growing CC531 metastases is superior to inhibit tumor growth compared to SYS.

Cetuximab, a novel anticancer agent, is a monoclonal human/ murine chimeric anti-epidermal growth factor receptor antibody, who is selectively active in the subpopulation of wild-type K-ras. EGF-R is overexpressed in colorectal cancer and correlates with a poorer prognosis and higher resistance to systemic chemotherapy [30-32]. Deregulation of EGF-R is linked to inhibition of tumor proliferation, invasion, migration, angiogenesis, and resistance to apoptosis [33]. The tumor cell line CC531, which was used in the present study, also expresses the EGF-R on its surface. As shown by the present study, cetuximab binds to EGF-R on the surface of the CC531 tumor cells.

In a preclinical trial, Van Buren et al. demonstrated that, after partial hemihepatectomy, a monoclonal EGF-R antibody had no effect on liver regeneration [34]. This view is in line with the results observed in the present study, where neither HAI nor SYS of cetuximab induced relevant side effects.

In clinical trials, intravenous cetuximab shows its efficacy in the treatment of colorectal liver metastases both as a single agent in second-line treatments as well as in combination with irinotecan- or oxaliplatin-based therapy regimens in first-line treatments [4, 5, 35-38]. Accordingly, today, intravenous application of cetuximab is clinical standard in the treatment of colorectal liver metastases, albeit restricted to wild-type K-ras cases. However, Azzopardi and coworkers claim that these results are still inconclusive. Even in patients with wild-type $\mathrm{K}$-ras an interindividual variability in response to cetuximab is observed [39]. In the present study, systemic application of cetuximab did not inhibit tumor growth. This is most probably due to the fact that the CC531 tumor cell line used exhibits a mutated K-ras gene in codon 12 (GGT to GAT), changing glycine to aspartic acid [40]. This is in line with the results of clinical studies, also demonstrating no significant effect of cetuximab on progression-free survival and overall survival in K-ras-mutated tumors [41]. Therefore, the results of our study are of particular interest because a comparable dose of cetuximab, when given via HAI, was not only capable of inhibiting the growth but also of decreasing the volume of the K-ras-mutated CC531 tumor. These in vivo results are supported by our in vitro analyses, demonstrating that, in high concentrations, cetuximab is capable of significantly reducing
CC531 cell viability. Because the application of the mAb by HAI provides an increased concentration, this might explain the unexpected observation of an increased antitumor effect in the present study.

In conclusion, the present study shows that HAI of cetuximab alone or in combination with oxaliplatin is effective to inhibit tumor growth of colorectal liver metastases in the rat, whereas SYS was ineffective. Thus, HAI chemotherapy with cetuximab and oxaliplatin may represent a promising approach in the treatment of colorectal liver metastases.

Acknowledgments We appreciate the excellent technical assistance of Janine Becker, Ruth Nickels, and Christina Marx.

Open Access This article is distributed under the terms of the Creative Commons Attribution License which permits any use, distribution, and reproduction in any medium, provided the original author(s) and the source are credited.

\section{References}

1. Harrison S, Benziger H (2011) The molecular biology of colorectal carcinoma and its implications: a review. Surgeon 9:200-210

2. Kopetz S, Chang GJ, Overman MJ, Eng C, Sargent DJ, Larson DW, Grothey A, Vauthey JN, Nagorney DM, McWilliams RR (2009) Improved survival in metastatic colorectal cancer is associated with adoption of hepatic resection and improved chemotherapy. J Clin Oncol 27:3677-3683

3. Seehofer D, Neuhaus P (2011) Current status of multimodal therapy for colorectal liver metastases. Zentralbl Chir 136:343-351

4. Van Cutsem E, Kohne CH, Hitre E, Zaluski J, Chang Chien CR, Makhson A, D'Haens G, Pinter T, Lim R, Bodoky G, Roh JK, Folprecht G, Ruff P, Stroh C, Tejpar S, Schlichting M, Nippgen J, Rougier P (2009) Cetuximab and chemotherapy as initial treatment for metastatic colorectal cancer. N Engl J Med 360:1408-1417

5. Bokemeyer C, Bondarenko I, Makhson A, Hartmann JT, Aparicio J, de Braud F, Donea S, Ludwig H, Schuch G, Stroh C, Loos AH, Zubel A, Koralewski P (2009) Fluorouracil, leucovorin, and oxaliplatin with and without cetuximab in the first-line treatment of metastatic colorectal cancer. J Clin Oncol 27:663-671

6. Garufi C, Torsello A, Tumolo S, Ettorre GM, Zeuli M, Campanella C, Vennarecci G, Mottolese M, Sperduti I, Cognetti F (2010) Cetuximab plus chronomodulated irinotecan, 5-fluorouracil, leucovorin and oxaliplatin as neoadjuvant chemotherapy in colorectal liver metastases: POCHER trial. Br J Cancer 103:1542-1547

7. Power DG, Healey-Bird BR, Kemeny NE (2008) Regional chemotherapy for liver-limited metastatic colorectal cancer. Clin Colorectal Cancer 7:247-259

8. Boige V, Malka D, Elias D, Castaing M, De Baere T, Goere D, Dromain C, Pocard M, Ducreux M (2008) Hepatic arterial infusion of oxaliplatin and intravenous LV5FU2 in unresectable liver metastases from colorectal cancer after systemic chemotherapy failure. Ann Surg Oncol 15:219-226

9. Ducreux M, Ychou M, Laplanche A, Gamelin E, Lasser P, Husseini F, Quenet F, Viret F, Jacob JH, Boige V, Elias D, Delperro JR, Luboinski M (2005) Hepatic arterial oxaliplatin infusion plus intravenous chemotherapy in colorectal cancer with inoperable hepatic metastases: a trial of the gastrointestinal group of the Federation Nationale des Centres de Lutte Contre le Cancer. J Clin Oncol 23:4881-4887

10. Elias D, Goere D, Boige V, Kohneh-Sharhi N, Malka D, Tomasic G, Dromain C, Ducreux M (2007) Outcome of posthepatectomy- 
missing colorectal liver metastases after complete response to chemotherapy: impact of adjuvant intra-arterial hepatic oxaliplatin. Ann Surg Oncol 14:3188-3194

11. Kemeny NE, Melendez FD, Capanu M, Paty PB, Fong Y, Schwartz LH, Jarnagin WR, Patel D, D'Angelica M (2009) Conversion to resectability using hepatic artery infusion plus systemic chemotherapy for the treatment of unresectable liver metastases from colorectal carcinoma. J Clin Oncol 27:3465-3471

12. Mocellin S, Pasquali S, Nitti D (2009) Fluoropyrimidine-HAI (hepatic arterial infusion) versus systemic chemotherapy (SCT) for unresectable liver metastases from colorectal cancer. Cochrane Database Syst Rev CD007823

13. Benedict FG (1934) Die Oberflächenbestimmungen verschiedener Tiergattungen [Determination of body surface area in different animal species]. Ergebnisse der Physiologie und Experimentellen Pharmakologie 36:300-346

14. Sperling J, Schafer T, Ziemann C, Benz-Weisser A, Kollmar O, Schilling MK, Menger MD (2012) Hepatic arterial infusion of bevacizumab in combination with oxaliplatin reduces tumor growth in a rat model of colorectal liver metastases. Clin Exp Metastasis 29(2):91-99

15. Reinacher-Schick AC, Bechstein WO (2007) Colorectal liver metastases. Neoadjuvant chemotherapy: aspects of medical and surgical oncology. Internist 48:51-58

16. Bouchahda M, Levi F, Adam R, Rougier P (2011) Modern insights into hepatic arterial infusion for liver metastases from colorectal cancer. Eur J Cancer 47(18):2681-2690

17. Bouchahda M, Adam R, Giacchetti S, Castaing D, BrezaultBonnet C, Hauteville D, Innominato PF, Focan C, Machover D, Levi F (2009) Rescue chemotherapy using multidrug chronomodulated hepatic arterial infusion for patients with heavily pretreated metastatic colorectal cancer. Cancer 115:4990-4999

18. Martin RC, Joshi J, Robbins K, Tomalty D, Bosnjakovik P, Derner M, Padr R, Rocek M, Scupchenko A, Tatum C (2011) Hepatic intraarterial injection of drug-eluting bead, irinotecan (DEBIRI) in unresectable colorectal liver metastases refractory to systemic chemotherapy: results of multi-institutional study. Ann Surg Oncol 18:192-198

19. Pohlen U, Buhr HJ, Berger G, Ritz JP, Holmer C (2011) Hepatic arterial infusion (HAI) with PEGylated liposomes containing 5-FU improves tumor control of liver metastases in a rat model. Invest New Drugs 30(3):927-935

20. Breedis C, Young C (1954) The blood supply of neoplasms in the liver. Am J Pathol 30:969-985

21. Burkel W (1970) The fine structure of the terminal branches of the hepatic arterial system of the rat. Anat Rec 167:329-349

22. Gonda T, Ishida H, Yoshinaga K, Sugihara K (2000) Microvasculature of small liver metastases in rats. J Surg Res 94:43-48

23. Okuno K, Hirai N, Lee YS, Tarabar D, Ueno H, Yasutomi M (1998) Superiority of hepatic arterial infusion in preventing catabolism of 5-FU compared with portal vein infusion revealed by an in vivo 19F NMR study. Cancer Chemother Pharmacol 42:341-344

24. Del Freo A, Fiorentini G, Sanguinetti F, Muttini MP, Pennucci C, Mambrini A, Pacetti P, Della Seta R, Lombardi M, Torri T, Cantore M (2006) Hepatic arterial chemotherapy with oxaliplatin, folinic acid and 5-fluorouracil in pre-treated patients with liver metastases from colorectal cancer. In Vivo 20:743-746

25. Kern W, Beckert B, Lang N, Stemmler J, Beykirch M, Stein J, Goecke E, Waggershauser T, Braess J, Schalhorn A, Hiddemann W (2001) Phase I and pharmacokinetic study of hepatic arterial infusion with oxaliplatin in combination with folinic acid and 5-fluorouracil in patients with hepatic metastases from colorectal cancer. Ann Oncol 12:599-603

26. de Gramont A, Figer A, Seymour M, Homerin M, Hmissi A, Cassidy J, Boni C, Cortes-Funes H, Cervantes A, Freyer G, Papamichael D, Le Bail N, Louvet C, Hendler D, de Braud F, Wilson C, Morvan F, Bonetti A (2000) Leucovorin and fluorouracil with or without oxaliplatin as first-line treatment in advanced colorectal cancer. J Clin Oncol 18:2938-2947
27. Hebbar M, Tournigand C, Lledo G, Mabro M, Andre T, Louvet C, Aparicio T, Flesch M, Varette C, de Gramont A (2006) Phase II trial alternating FOLFOX-6 and FOLFIRI regimens in second-line therapy of patients with metastatic colorectal cancer (FIREFOX study). Cancer Invest 24:154-159

28. Tournigand C, Cervantes A, Figer A, Lledo G, Flesch M, Buyse M, Mineur L, Carola E, Etienne PL, Rivera F, Chirivella I, Perez-Staub N, Louvet C, Andre T, Tabah-Fisch I, de Gramont A (2006) OPTIMOX1: a randomized study of FOLFOX4 or FOLFOX7 with oxaliplatin in a stop-and-Go fashion in advanced colorectal cancer-a GERCOR study. J Clin Oncol 24:394-400

29. Omura K (2008) Advances in chemotherapy against advanced or metastatic colorectal cancer. Digestion 77(1):13-22

30. Ciardiello F, Tortora G (2003) Epidermal growth factor receptor (EGFR) as a target in cancer therapy: understanding the role of receptor expression and other molecular determinants that could influence the response to anti-EGFR drugs. Eur J Cancer 39:13481354

31. Gross ME, Shazer RL, Agus DB (2004) Targeting the HER-kinase axis in cancer. Semin Oncol 31:9-20

32. Ritter CA, Arteaga CL (2003) The epidermal growth factor receptor-tyrosine kinase: a promising therapeutic target in solid tumors. Semin Oncol 30:3-11

33. Ng M, Cunningham D (2004) Cetuximab (Erbitux)—an emerging targeted therapy for epidermal growth factor receptor-expressing tumours. Int J Clin Pract 58:970-976

34. Van Buren G 2nd, Yang AD, Dallas NA, Gray MJ, Lim SJ, Xia L, Fan F, Somcio R, Wu Y, Hicklin DJ, Ellis LM (2008) Effect of molecular therapeutics on liver regeneration in a murine model. J Clin Oncol 26:1836-1842

35. Arnold D, Hohler T, Dittrich C, Lordick F, Seufferlein T, Riemann J, Woll E, Herrmann T, Zubel A, Schmoll HJ (2008) Cetuximab in combination with weekly 5 -fluorouracil/folinic acid and oxaliplatin (FUFOX) in untreated patients with advanced colorectal cancer: a phase Ib/II study of the AIO GI Group. Ann Oncol 19:1442-1449

36. Cunningham D, Humblet Y, Siena S, Khayat D, Bleiberg H, Santoro A, Bets D, Mueser M, Harstrick A, Verslype C, Chau I, Van Cutsem E (2004) Cetuximab monotherapy and cetuximab plus irinotecan in irinotecan-refractory metastatic colorectal cancer. $\mathrm{N}$ Engl J Med 351:337-345

37. Folprecht G, Lutz MP, Schoffski P, Seufferlein T, Nolting A, Pollert P, Kohne CH (2006) Cetuximab and irinotecan/5-fluorouracil/folinic acid is a safe combination for the first-line treatment of patients with epidermal growth factor receptor expressing metastatic colorectal carcinoma. Ann Oncol 17:450-456

38. Lenz HJ, Van Cutsem E, Khambata-Ford S, Mayer RJ, Gold P, Stella P, Mirtsching B, Cohn AL, Pippas AW, Azarnia N, Tsuchihashi Z, Mauro DJ, Rowinsky EK (2006) Multicenter phase II and translational study of cetuximab in metastatic colorectal carcinoma refractory to irinotecan, oxaliplatin, and fluoropyrimidines. J Clin Oncol 24:4914-4921

39. Azzopardi N, Lecomte T, Ternant D, Boisdron-Celle M, Piller F, Morel A, Gouilleux-Gruart V, Vignault-Desvignes C, Watier H, Gamelin E, Paintaud G (2011) Cetuximab pharmacokinetics influences progression-free survival of metastatic colorectal cancer patients. Clin Cancer Res 17(19):6329-6337

40. van Etten B, ten Hagen TL, de Vries MR, Ambagtsheer G, Huet T, Eggermont AM (2002) Prerequisites for effective adenovirus mediated gene therapy of colorectal liver metastases in the rat using an intracellular neutralizing antibody fragment to $\mathrm{p} 21-\mathrm{Ras}$. Br J Cancer 86(3):436-442

41. Karapetis CS, Khambata-Ford S, Jonker DJ, O'Callaghan CJ, Tu D, Tebbutt NC, Simes RJ, Chalchal H, Shapiro JD, Robitaille S, Price TJ, Shepherd L, Au HJ, Langer C, Moore MJ, Zalcberg JR (2008) K-ras mutations and benefit from cetuximab in advanced colorectal cancer. N Engl J Med Oct 359(17):1757-1765 